\title{
Leadership in the Context of a New World: Digital Leadership and Industry 4.0
}

Christoph Bach

Comenius University in Bratislava, Slovak Republic

ch.bach-frankfurt@t-online.de

Rozália Sulíková

Comenius University in Bratislava, Slovak Republic

rozalia.sulikova@fm.uniba.sk

This paper attempts to address and critically examine a current concept of leadership in business studies: digital leadership. Researchers often say that this is a new leadership style and that there is a necessity for such a new style because the entrepreneurial environment has changed considerably with digitisation, but also with Industry 4.0, which to a certain extent coincides with digitisation, and the concept of a so-called VUCA (Volatile, Uncertain, Com-plex and Ambiguous) world. The conclusion drawn here could be summarised as follows: a changed business environment forces companies to react, namely with a new way of leading - digital leadership. This study will show that such a concept is by no means new, as research claims, but rather has been in existence for more than 150 years. What many researchers understand by digital leadership, apart from the demand for driving forward digitisation, coincides with the leadership principle introduced by Prussian General Moltke, known as 'mission-type tactics.' One of the aims of this paper is to demonstrate this. It will also be shown that digital leadership, in contrast to transformational leadership, can be acquired and that digital leadership cannot be classified in the opposition to transformational or transactional leadership, but is rather to be held and understood as a third variant. Only a prescriptive method based on understanding seems to be a suitable method.

Key Words: digital leadership, industry 4.0, smart factory, digitisation, VUCA, transactional leadership, transformational leadership, mission-type tactic, ambidexterity, competence JEL Classification: D23, J81, L20, M12, O15

((c) Br.SA https://doi.org/10.26493/1854-6935.19.209-226

\section{Introduction}

Rapid technological progress that has taken place in recent years and decades, and above all the accompanying change in the economic world, 
has left its mark on economic research. Due to the constant increase in the degree of digitisation, new possibilities are arising in production today; this is being discussed in research under the heading 'Industry 4.0' (Deckert 2019). The emergence of this new type of industry is correlated with a world that has become more uncertain and volatile; this phenomenon is being discussed in research under the keyword ' $\mathrm{VUCA}$ (Volatile, Uncertain, Complex and Ambiguous) world' (Mack and Khare 2016). From the perspective of a company, this means that the external world is not only in a constant state of flux, but that economic activity as a whole has become more risky, and at the same time the internal world is changing, insofar as digitisation not only opens up new production methods, but virtually demands them.

Both factors, Industry 4.0 and a VUCA world, require a new way of leading. This new way of leadership is being discussed in research under the keyword 'digital leadership' (Wagner 2018). This study aims to show that digital leadership is by no means as new as most people claim; what is also congruent with this is the fact that a VUCA world is also by no means as new as it is claimed. Only Industry 4.0 seems to open up new perspectives, but here, too, we should not speak of a truly new industrial revolution.

\section{Method}

Economics in general and business studies in particular must be understood as a social science or part of the humanities, since its object is the order, processing and interpretation of a sphere of life and thus differs from the natural sciences, whose objects of study are physical objects (Bardmann 2019, 85). To a certain extent, all humanities are interdisciplinary in orientation, but business studies in particular is interdisciplinary, which can be seen in its proximity to psychology (Kahneman 2012) or even the social sciences (Bardmann 2019, 86); likewise, the term 'economic sociology' indicates a general proximity of these two sciences. Questions about what leadership is, for example, can be treated scientifically in neither economic nor psychological terms, but can nevertheless be looked at from a sociological point of view, because sociology does look - though not only - at the foundations of human coexistence. Therefore, it should not come as a surprise that works dedicated to this topic, whether explicitly or implicitly, always return to sociology.

In German sociology, the early 1960 s saw the so-called 'positivism dispute, led mainly by Adorno on the one side and Popper on the other 
(Adorno, Habermas, and Popper 1972). Popper gave preference to an empirical method, drawing on Hempel and Oppenheim's research: to grasp a fact scientifically means to deduct it from scientific laws, taking conditions of application into account (Hempel and Oppenheim 1948), which is also understood as 'explaining.' An explaining interpreted in this way was rejected by Popper's antagonists, since this was a 'positivistically halved rationalism' (Habermas 1972, 235). Now it seems that, according to what has been said, Popper's antagonist, Adorno, should provide the methodology to be brought into play here. However, it quickly becomes clear to those who study Adorno more closely that the dialectics of the Frankfurt School can hardly solve the issues to be discussed here. This work does not intend to take a position on the positivism dispute; nevertheless, it should be noted that this dispute has never been resolved. This suggests that both empirical and non-empirical methods, i.e. traditional methods in humanities, certainly have a right in sociology and thus also in economics. And indeed, the question of what leadership is cannot be answered, either by economic science or empirically. It cannot be deduced from scientific laws what leadership is. As a consequence, it cannot be explained exactly what leadership is.

Explaining something therefore means establishing a causal connection, which at the end will lead to a proper explanation. However, explanations always presuppose that what is to be explained has already been understood and is thus prior to explaining. The art of understanding has a long historical tradition, beginning with Dilthey (1959) and extending through Heidegger (1993), Gadamer (1965) and finally Hösle (2018) to the present. While the early representatives of the art of understanding, or hermeneutics, related it primarily to texts, with Heidegger at the latest, understanding also and above all relates to the world. Hermeneutics is not only the art of understanding texts or works of art; it is not only the foundation of the humanities (which it certainly is, too), it also refers to understanding the world and what people encounter in the world. It becomes clear: people are and have always been capable of understanding the world. Nevertheless, there are different degrees of understanding. Hermeneutics is the attempt to make clear what is to be understood and, precisely through this, to arrive at a better understanding of what is to be understood. As such, it can also be made fruitful for non-philosophical areas, such as business administration.

In addition to the positivism dispute, reference must also be made to the 'value judgement controversy' that broke out in the early 190os. On 
the one side there is the position that no recommendations for action can be derived from a constant expansion of knowledge about causal relationships. The other side claimed exactly this (Bardmann 2019, 75). This dispute can ultimately be reduced to the following question: should economics be descriptive or prescriptive? (Bardmann 2019, 76). What becomes clear is that this dispute, too, is at its core a methodological dispute, and like the value judgement controversy, it has by no means been resolved to this date. This suggests that both prescriptive and descriptive methods can be quite scientific, depending on what the question is.

Especially in German research on business administration, there has been an approximation to the methods of the humanities in recent decades (Julmi 2020, 96); this is by no means to be seen as a devaluation of a method based on the natural sciences, but rather as a necessary complement to them. German business studies in particular, in contrast to Anglo-American business studies, seeks a uniform foundation for its discipline. Anglo-Saxon business studies, on the other hand, is so fragmented into its sub-areas (e.g. marketing, management or materials management) precisely because it does not seek such a foundation that it is hardly possible to speak of a systematic connection between these subareas (Julmi 2020, 97). This work, insofar as it understands itself to be in the German tradition, attempts to methodically join the humanities, more precisely hermeneutics, in order to understand what constitutes leadership in general and digital leadership in particular. Hermeneutics in the context of business management cannot therefore consist of gaining cognitive goals and hypotheses or suggesting explanatory explications of facts; rather, it attempts to consider facts in their relationship to higher-level systems (Julmi 2020, 109).

The following work is thus dedicated to the concept of leadership; it follows from what has been said that the method is one of understanding. Furthermore, it cannot be the task to approach leadership in a purely descriptive way. Against the background of Industry 4.0, as well as a V UCA world, it is by no means sufficient to merely describe leadership techniques and styles. In this respect, it is prescriptive in the broadest sense. The methodology of the present work is therefore prescriptive and based on understanding.

\section{Industry 4.0, Smart Factory and v U CA}

The question of leadership and the accompanying question of a new leadership style is connected with changes that not only the business world 
has experienced in recent years and decades. These changes can be described by using the following three terms: Industry 4.0, Smart Factory and VUCA. These terms will be briefly explained first.

\section{INDUSTRY 4.0}

With the onset of digitisation in the 1970s, a profound change in the world of work began. In this respect, it is not surprising that this is often also viewed as another industrial revolution. Open-plan offices, for example, are the exception today, but they used to be the rule, at least in large companies. Industry 4.0 is often referred to as the fourth industrial revolution (for example, in Pistorius 2020, 5). It is the logical continuation of a previous digitisation, which began with the advent of computers and the second step of which was the Internet. 'By digitising classic industrial companies, the aim is to increase automation and networking in production' (Pistorius 2020, 5). In other words, while digitisation has so far mainly taken place in the office and then in sales, in the course of Industry 4.0 production will also be digitised. The aim, as Schuh et al. (2020, 469) say, in the context of the vision of an 'Internet of Production' (IoP) developed at RWTH Aachen University, is 'to reach a new level of cross-domain collaboration that, by means of semantically correct, context-aware data is not just unique, but is achieved continuously and highly iteratively in real time with the appropriate granuality'.

According to industry associations such as Bitkom, VDMA and ZVEI, Industry 4.0 can be described as follows (Pistorius 2020, 6):

The term Industry 4.0 stands for the fourth industrial revolution, a new level of organisation and control of the entire value chain over the life cycle of products. This cycle is based on the increasingly individualised customer requirements and extends from the idea, the order, through the development and production, the delivery of a product to the end customer [...], including the associated services.

\section{SMART FACTORY}

In addition to Industry 4.o, the term 'Smart Factory' is often used. Although this term appears frequently in research, it has different connotations; thus, it can be understood as a 'ubiquitous factory', a smart factory of the future, a technological approach or a paradigm (Radziwon et al. 2014, 1185). Radziwon et al. (2014, 1187) give the following definition:

A Smart Factory is a manufacturing solution that provides such flexible and adaptive production processes that will solve problems arising on 
a production facility with dynamic and rapidly changing boundary conditions in a world of increasing complexity. This special solution could on the one hand be related to automation, understood as a combination of software, hardware and/or mechanics, which should lead to optimization of manufacturing resulting in reduction of unnecessary labour and waste of resources. On the other hand, it could be seen in a perspective of collaboration between different industrial and nonindustrial partners, where the smartness comes from forming a dynamic organization.

On the one hand, this definition makes it clear that there is a connection between Industry 4.0 and Smart Factory. On the other hand, this definition establishes the connection to the VUCA term in the following sub-chapter, which characterises today's world in more detail.

\section{VUCA}

VUCA is an abbreviation meant to characterise today's world, which is mainly defined by four factors (Unkrig 2020, 6; Mack and Khare 2016, 5):

- Volatility - indicates the rapid rate of change in the pattern of dynamics observed in socio-economic systems. This also includes the strong fluctuations in macro-economic conditions, the financial markets and raw material prices. In this context, it is not insignificant that volatility develops unexpectedly.

- Uncertainty - the effects of uncertainty manifest themselves primarily in unpredictability, uncontrollable developments, and a lack of understanding of relationships. In particular, the uncertainty and feedback and interactions that are inherent in social systems are particularly evident. There are several factors that act as a further reason for the uncertainty or at least as a catalyst: past mistakes, rejection, social fears and finally perfectionism.

- Complexity - is fundamentally dependent on the number of factors, the type and number of interrelationships, the number of unknowns and, finally, the degree of uncertainty. Complexity often relates to network structures and the dynamic connections between the components of the system.

- Ambiguity - is the blurring of reality and the potential for misinterpretation. This is often incomprehensible and can no longer be planned. What could be relevant in the future is uncertain, ambiguous and hardly predictable. It becomes clear that the various points mentioned are interdependent: uncertainty also results from volatil- 
ity and complexity, and these two points also have an impact on ambiguity. At the same time, there should be a connection between volatility and ambiguity. If one wanted to summarise vUCA accordingly, one would have to say that a VUCA world does not offer absolute certainties, which represents a fundamental risk for all economic activities.

With Industry 4.0 and VUCA, problems and challenges that modern executives are faced with become clear. The changes in production processes, which in the near future every bigger company will have to carry out before the horizon of a VUCA world, seem to require different types of management.

VUCA and Industry 4.0 are not systematically related, but it is clear that these two terms indicate supposedly new challenges that managers are faced with. Roughly speaking, one could say that VUCA names the environment of a modern company; Industry 4.0, on the other hand, affects the (coming) inner world of modern companies.

\section{A New Way of Leading People: Digital Leadership}

Against the backdrop of Industry 4.0, v U C A or Smart Factory, the question of a new way of leading seems almost necessary: due to the changed internal and external environment of companies, it is no longer possible to lead in the same way as before. Changed environments require different ways of leading. Leadership must adapt to this. But what is leadership? Kauffeld $(2011,68)$ elucidates: 'Leadership serves to individually and purposefully influence, motivate and/or enable others to contribute to the achievement of collective goals in organisations.' Bea $(2011,2)$ also defines the term in this sense: 'Leadership is a goal-oriented shaping of companies (= corporate management) or goal-oriented influencing of people'.

In the classic literature on leadership, two leadership styles are distinguished from each other: the transactional and the transformational leadership style. The transactional leadership style understands leadership as an exchange relationship. The leader rewards performance on the basis of a contract, in the form of money, promotion, praise, appreciation, etc. The manager rewards performance or punishes when predetermined performance is not met. Burns $(1978,19)$, who introduced the term, defines it in these terms. One can speak of transactional leadership 'when a person takes the initiative in making contact with others for the purpose of an exchange of valued things. This exchange can be economic, 
political or psychological in nature.' This is to be distinguished from the transformational leadership style. This style attempts to increase performance through transformations of values, attitudes, etc. Leaders who use this style try to control the behaviour of their subordinates through vision. They possess charisma and exude great self-confidence. The implementation of their vision is at the centre of their activities. They are able to create an atmosphere of trust and confidence, which is necessary to achieve high goals. Subordinates can be characterised by a high degree of loyalty and personal dedication. It should be emphasised, however, that the success of charismatic leaders depends to a large extent on whether the lofty goals can actually be achieved (Dems 2015).

There are therefore two points at which leadership starts: (a) Leadership is understood according to the do ut des principle (Latin for: 'I give in order that you may give'). One could also say that the leader does not want to reach the core of the subordinates, but only proceeds externally: achieving predetermined goals is rewarded, if employees fail to achieve these goals they are punished. (b) Leadership wants to do exactly that: to influence the person being led in such a way that their motivation is not primarily fed by expected reciprocity. One could also say that the motivation of the person led in the first case is extrinsic, while in the second case it is intrinsically fed.

Digital leadership is to be distinguished from these classic leadership principles. First of all, however, it should be noted that a completely different style of leadership seems to be necessary: with the digitisation of the world of work and life, the two principles mentioned above are proving to be outdated. In this sense, Kollmann (2020, 34), for example, says that the digital leader 'is now characterised by wanting a digital transformation (digital mindset), mastering the use of digital technologies (digital skills) as well as consistently implementing the resulting measures within the framework of the digital transformation. Digital leadership thus includes a focus on new technologies; in this sense, it should be emphasised that digital leaders anticipate technical developments and communicate this internally as well as externally through a meaningful vision. Digital leaders can integrate phenomena that relate to society as a whole into their business model (Kreutzer, Neugebauer, and Pattloch 2017, 46).

Doyé $(2020,211)$ believes that digital companies should not be led traditionally, but instead need a different style of leadership, one that involves more cooperation, understanding, inclusion, and mediation, i.e. 
collaborative leadership. For digital leaders, the rule is: 'Give up control, but retain leadership' (Doyé 2020, 212).

As Doyé and many other authors emphasise, digital leadership means giving employees responsibility and not only maintaining freedom, but also creating it if necessary. Digital leaders rely on employees and no longer on a top-down structure (Doyé 2020, 213). They want to be involved when it comes to important decisions. Furthermore, it is about making the performance of individual team members more transparent and introducing a more results-oriented remuneration. For Generation $\mathrm{Y}$ and also $\mathrm{Z}$, work-life balance has a completely different meaning than for the generations before (Doyé 2020, 214).

Creusen, Gall, and Hackl $(2017,210)$ take a somewhat different view. They also emphasise that it is no longer possible to lead transactionally and that changes are imminent due to digitisation. However, in their view, change comes from the leader. They further point out that the success of the group as well as the whole company ultimately depends on the attitudes and values of the members. Therefore, for them, digital leadership is linked to the values and culture that are lived in the company. Above all, the question of power and how leaders deal with it comes up in this context (Creusen, Gall, and Hackl 2017, 210).

Overall, it becomes clear that digital leadership differs above all from transactional leadership. Following this, two aspects can be identified that distinguish digital leadership from other types of leadership.

1. Digital leadership means that the digital transformation is driven forward. New technologies are introduced into the company. This first point is directed, if one wants to use a metaphor that is certainly not misleading in this context, at the hardware of the company.

2. Digital leadership also means that subordinates must be given more freedom. This metaphorically refers to the company's software.

Digital leadership, therefore, focuses on the entire company and not just on the expansion of the digital infrastructure. While the first point refers to Industry 4.0 and Smart Factory, the last point is directed at a VUCA world. Only companies whose employees are not managed transactionally can be successful in such a world in the long term. It now seems obvious that digital leadership would have to fall back on transformational leadership. However, it must be stressed here that this depends on the personality of the leader. Charisma, the central aspect of a transformational leadership, is something that cannot be learned. 


\section{A Truly New Way of Leadership?}

What is it that distinguishes leaders from their subordinates? First of all, one might think of the hierarchy in companies. Leaders are on a higher level in the hierarchy than their subordinates. It should be noted here that the hierarchy is a hierarchy within the company. Sociologically speaking, a company is an organisation. First of all, this is a special form of social entity that differs from other social entities such as families, groups, networks, protest movements or even the nation state (Kühl 2011, 13). Abraham and Büschges come up not only with a negative, but also a positive definition. They call organisations associations of people that have three characteristics in common: they have given themselves the tasks of realising specific purposes, they are structured according to the division of labour, and they are equipped with a governing body that is responsible for representing the organisation internally and externally (Abraham and Büschges 2009, 21). The crucial point here is that hierarchies belong to every organisation and thus also to the enterprise, which the authors call a management authority. Accordingly, to have a leadership function in a company means also to have a leadership function within an organisation.

Leaders, however, can only act as leaders because they possess certain characteristics that enable them to do so, at least in an ideal scenario. These characteristics are usually called competencies. First of all, it should be noted here that every employee must of course have certain competences, because only those who have them can also fulfil the tasks imposed on them. Therefore, the focus here is on the so-called leadership competences. The general characteristic of competences is that they enable action, which distinguishes them from skills and abilities, among other things (Heyse, Erpenbeck, and Ortmann 2015, 13).

Inasmuch as leadership is always related to action, ultimately leadership always means acting; leadership competencies can be discovered that are clearly different from employee competencies. Hardegger, Boss, and Siano (2018) list a total of 13 competencies, which they divide into four dimensions. These are: values, thinking, acting and interacting. ${ }^{1}$ They then

1. It should be noted here that action as a competence dimension and the ability to act must be distinguished: Action as a dimension does not so much refer to the ability to act, but to the way in which action takes place. Acting at all is therefore not yet a leadership competence; acting in the sense of the company requires specific competences that are defined in the dimension of acting and determine the manner of this action. 
place these dimensions in the context of the most well-known types of leadership in economics, namely a transactional and a transformational one.

A look at these competence dimensions now reveals that one - in many ways important - dimension seems to be missing: in times of VUCA and above all of Industry 4.0, should not the aforementioned competence catalogue be expanded to include the dimension of 'digital competence'? In any case, it is obvious that digitisation will change the world of work. For example, one prediction is that the external framework conditions of companies will change, as markets or even the relationship with customers change. More importantly, however, the internal framework conditions will also change; a flexibilisation of the working world, both in terms of location and time, will increase, which will have an impact on corporate culture (Fleig 2020, 7).

The concrete competences are of less interest in this context; however, it can hardly be denied that the general handling of PCs, mobile devices or data protection and security will become even more important than they already are today. Therefore, digital competences will play a major role within future companies. More important in this context, however, is whether this will be accompanied by a fundamental change in management culture. In other words: will fundamentally different competences have to prevail among management personnel due to a foreseeable intensification of digitisation? Furthermore: will a completely different leadership style have to be established due to the predicted vUCA world, which is definitely related to Industry 4.0?

When it was said above that digital leadership means that digital change is driven forward and that employees give their subordinates more freedom, from the perspective of leadership competences digital change is a comparatively minor problem. Allowing employees greater freedom, however, seems to point to a much bigger problem. In a certain sense, one could say that competencies of leaders consist of not acting themselves in a narrower sense, but rather letting them act. One could also put this differently: the task of leaders is to set goals that the subordinates have to achieve with the resources allocated to them. How they achieve these goals, however, is not specified by the leaders. The only thing that is important is that they are actually achieved.

In the context of a VUCA world, companies are facing major problems. On the one hand, they must continue to focus on their core business, but on the other hand, it is equally necessary for them to be or become 
competitive in terms of new business areas. In concrete terms, this means that on the one hand they must be able to efficiently manage and maintain the current existing business (exploitation) and on the other hand maintain an agile approach to changes in the innovation business, if not even become a player in this field themselves (exploration). Kollmann calls this double task, which companies already have to face today, 'digital ambidexterity' (Latin for 'using both hands') (Kollmann 2020, 33). This ambidexterity must go hand in hand with different leadership styles. The current core business might require different leadership methods than driving digital innovations and their marketing. What Kollmann diagnoses here is that at least larger companies cannot be managed with just one leadership style, since every company is always already faced with two tasks: on the one hand, to continue to expand the existing and core business and, on the other hand, to react to change or to drive it forward. These two aspects of entrepreneurial activity are not, or only with difficulty, compatible in the leadership style of one person, because this would mean that the same person would apply different standards to their subordinates, depending on whether they drive innovation or the core business.

Kollmann, who has also recognised this problem, names transactional, directive and expert-oriented leadership styles that have proven themselves in the area of existing business, while transformational, ethical, strategic and ultimately digital leadership styles are necessary for the innovation business.

After what has been said, it can first be stated that digital leadership cannot be used to manage the entire company. Digital leadership makes a company fit for the future. It is the answer to a VUCA world, or one could also say that digital leadership is required in the context of what Schumpeter understands by 'creative destruction. Digital leadership is thus the answer to a dynamic market in which companies try to establish themselves on the market with new products or new production methods. However, in a market that is less dynamic and more static, where products meet consumer demands, digital leadership could be detrimental because, as should be mentioned here, the introduction of new products and new production methods is always associated with a risk.

This, however, should not be discussed here in any more detail. There is no question that at least larger companies must face up to the digital transformation. But what exactly is digital leadership? Is it really about driving forward the digital transformation? The distinction has just been 
made between two leadership styles, with transformational leadership and digital leadership sorted into one class and transactional leadership into the other, which ultimately leads to the question as to why transactional leaders should not be able to drive digital change. It turns out that digital leadership actually means more than that. As already said above, digital leadership involves a completely different style of leadership. Digital leadership also means leading collaboratively, handing over responsibility, etc., as mentioned before. Digital leadership is therefore by no means necessarily associated only with the digitisation of companies. Rather, it is a way of leading that is practised above all - at least it seems so - in companies based in Silicon Valley. This way of leading, however, does not necessarily require a digital background. Digitisation is therefore a necessary but by no means sufficient condition for digital leadership.

What can be considered a necessary condition for digital leadership, i.e. what makes a digital leader, will now be briefly considered. Leading is always about leading people. This also applies to leaders who see themselves as digital leaders, who also lead people. This is also illustrated by the fact that companies are organisations. According to the above, an organisation is an association of people that want to achieve specific purposes. However, purposes are not set by computers, but by people. In this sense, the desired digital transformation of a company is a purpose; this also shows that digital leadership cannot be reduced to implementing digitisation in a company. This has already been said above. It was emphasised that digital leadership also means giving up control and yet retaining leadership.

In that respect, a way of leading seems to become apparent that can by no means be described as new; on the contrary, it is quite familiar, even if this was introduced in a completely different field, namely in the military. The Prussian General Moltke, who contributed significantly to Prussia's success in the German wars of unification (the German-Danish War of 1864, the Prussian-Austrian War of 1866 and finally the German-French War of 1870-1) by his way of leading troops, writes in the Verordnungen für die höheren Truppenführer (ordinances for senior troop leaders): 'In general, one will not give any more orders than is absolutely necessary, not to plan beyond any circumstances, which can be overlooked, for these change quickly in war and rarely will orders that go far ahead and into detail be fully carried out in time' (Moltke 1993, 443; original emphasis).

In the context of interest here, it is above all decisive that Moltke urges 
his subordinates to order only what is necessary, since in a war the situation can change quickly. War is certainly an example of a VUCA world, although this is not to say that every VUCA world is in a state of war. Nevertheless, the reference that only what is absolutely necessary should be ordered, since one can never view everything that is essential, is also quite important in a business context, because at least for larger companies it is also true that the leaders can never view everything that is important and therefore it can also be assumed here that orders that go into great detail will either not be carried out fully or, if they are, the risk that they are rather disadvantageous for the company is extremely high.

Moltke (1993, 443) continues: 'It shakes the confidence of the subordinate leaders and gives the troops a feeling of insecurity when things turn out quite differently from what the higher command had foreseen.' Moltke thus draws attention to psychological consequences when directives and orders seem pointless because they do not correspond to the situation. Again, this can be applied to companies: trust in management is also likely to be shaken if orders do not fit the current situation and thus appear to be meaningless. Moltke goes on to say, 'Moreover, it must not go unnoticed that when one gives a lot of orders, it is very easy for the important things, the things that must absolutely be carried out, to be obscured by the mass of secondary things and things that are only valid under certain circumstances, and to be carried out only incidentally or not at all' (Moltke 1993, 443). The more orders are given, especially if they obviously refer to secondary matters, the higher the probability that the orders will not be carried out at all or will be carried out inadequately. Instead, the leader of a military unit must focus on what is important. This, too, can easily be transferred to the leadership of companies.

Following Moltke, it can be said that leadership consists of concentrating on what is essential. Leaders are encouraged to order only what is absolutely necessary. As a result, orders are general and do not go into detail. This way of leading is known as 'leading by mission' (or mission-type tactics) and is different from 'leading by orders' (order tactics). Leading by mission means that the subordinates understand the meaning of an order and are therefore not only able to act on their own authority if the situation changes, but are actually encouraged to do so. Leading by orders is in complete opposition to this. Here the subordinate has to carry out the order literally.

It becomes clear that mission-type tactics means giving subordinates an order and then having confidence in them that the goal will be 
achieved. Mission-type tactics therefore mean relinquishing control and yet leading. However, this was stated above as one of the definitions of digital leadership. According to what has been said so far, digital leadership - especially in the context of a VUCA world - seems to be the right way of leadership, because it can be used to react flexibly to new challenges, even and especially those that had not been foreseen. If, however, the thesis is accepted that in the end there is no difference in the decisive aspects between digital leadership and leading by mission, then it has been made clear that these two ways of leading are one and the same. And thus digital leadership is by no means as new as many authors believe.

The fact that digital leadership, as explained here, and transformational leadership overlap in large areas, has become obvious. The question remains whether digital leadership can also be transactional. As said, transactional leadership is based on the do ut des principle, i.e. on the principle of performance and return. As a matter of fact, there is no reason why transactional leadership and digital leadership should exclude each other, because transactional leadership in fact does not mean giving instructions down to the smallest detail, which then have to be implemented by the subordinates. The concept of digital leadership is actually at odds with the distinction between transactional and transformational leadership.

When we come back to digital ambidexterity, it now becomes clear what is meant by this: digital leadership can be used both in the existing business and in the innovation business. This means not only - and this should be emphasised once again - that digitisation is driven forward, but also that leadership hands over power and responsibility to subordinates in order to benefit in return from their creativity, flexibility and sense of responsibility. It makes no difference whether the subordinates' motivation is primarily a material one or primarily driven by the visions of their superior.

Finally, something else should be pointed out. It was said above that transformational leadership cannot be learned because it depends on the charisma of the leader. Although digital leadership and transformational leadership overlap, they are not identical. Digital leadership does not require a charismatic leader. Rather, it requires specific competencies; but these can be learned. In other words, while only a relatively small number of leaders can actually lead in a transformational way, in principle anyone can lead in a digital way, albeit under certain conditions. 


\section{Conclusion and Prospects}

This paper shows that digital leadership and leading by mission are one and the same. So when scientists talk about the need for a new way of leading in the context of a VUCA world or Industry 4.0, they disregard the fact that the required new way of leading is by no means new, because it coincides with mission-type tactics. The only new aspect that can be mentioned is the advancement of digitisation. But ultimately, this can only be described as something new from a material point of view, not from a formal one; after all, this illustrates exactly what Schumpeter tried to capture under the term 'creative destruction' (Schumpeter 2018, 113).

Digital leadership and leading by mission are the same thing; that is one result of what has been examined in this paper. The other result, even if it is just a secondary result, is that digital leadership, unlike transformational leadership, can be learned. Insofar as leadership is always linked to competences, the question naturally arises as to which competences are decisive here and should therefore have to be acquired. This question, as important as it is, cannot be answered at this point and must therefore be postponed to a later date.

Another result of this work is that the two categories with which leadership styles are usually characterised, i.e. transformational and transactional leadership, are perhaps too simplistic to capture the phenomenon of leadership scientifically. It should be noted here that research naturally knows far more leadership styles; however, as was the case in this work, these are often assigned to one of the two styles mentioned. The term digital leadership, on the other hand, introduces a style that defies such categorisation. Both transactional and transformational leadership are compatible with digital leadership.

Finally, it should be pointed out that digital leadership, understood as leading by mission, does have certain similarities with 'management by objectives' introduced by Drucker (1954). Nevertheless, attention should be drawn here to an important difference: Drucker's management concept is clearly to be assigned to the transactional style. In this respect, this management concept and digital leadership are not the same. The perhaps only small but nevertheless decisive differences between these two styles, however, cannot be discussed here in any more detail.

\section{References}

Abraham, M., and G. Büschges. 2009. Einführung in die Organisationssoziologie. 4th ed. Wiesbaden: vs Verlag für Sozialwissenschaften. 
Adorno, T. W., J. Habermas, and K. R. Popper. 1972. Der Positivismusstreit in der deutschen Soziologie. 6th ed. Darmstadt: Luchterhand.

Bardmann, M. 2019. Grundlagen der Allgemeinen Betriebswirtschaftslehre: Geschichte - Konzepte - Digitalisierung. 3th ed. Wiesbaden: Springer Gabler.

Bea, F. X. 2011. Allgemeine Betriebswirtschaftslehre. 1oth ed. Stuttgart: U т B. Burns, J. M. 1978. Leadership. New York: Harper \& Row.

Creusen, U., B. Gall, and O. Hackl. 2017. Digital Leadership: Führung in Zeiten des digitalen Wandels. Wiesbaden: Springer Fachmedien.

Deckert, R. 2019. Digitalisierung und Industrie 4.o: Technologischer Wandel und individuelle Weiterentwicklung. Wiesbaden: Springer Fachmedien.

Dems, K. 2015. 'Famous Examples of Different Leadership Styles.' http:// www.brighthub.com/office/home/articles/76450.aspx.

Dilthey, W. 1959. Einleitung in die Geisteswissenschaften: Versuch einer Grundlegung für das Studium der Geschichte und der Gesellschaft. 4th ed. Stuttgart: Teubner Verlagsgesellschaft.

Doyé, T. 2020. 'Digital Leadership.' In Digitalisierung in Industrie und Handels und Dienstleistungsunternehmen, edited by L. Fend and J. Hofmann, 207-24. Wiesbaden: Springer.

Drucker, P. F. 1954. The Practice of Management. New York: Harper \& Row.

Fleig, M. 2020. eLearning Benchmarking Studie 2020 - Teilstudie: Digitale Kompetenzen zwischen Trend und Praxisalltag. Hagen im Bremischen: Siepmann.

Gadamer, H.-G. 1965. Wahrheit und Methode. 4th ed. Tübingen: J. C. B. Mohr.

Habermas, J. 1972. 'Gegen einen positivistisch halbierten Rationalismus.' In Der Positivismusstreit in der deutschen Soziologie, edited by T. W. Adorno, 235-66. 6th ed. Darmstadt: Luchterhand.

Hardegger, S. C., P. Boss, and R. Siano. 2018. 'Führungskompetenz worauf es wirklich ankommt: Worauf kommt es beim Führen wirklich an? Antwort gibt die Verbindung von Forschung und Expertise aus der Praxis.' In Psychologie des Unternehmertums: Der Mensch im Unternehmen; Impulse für Fach- und Führungskräfte, edited by C. Negri, 94-109. Wiesbaden: Springer.

Heidegger, M. 1993. Sein und Zeit. Tübingen: Max Niemeyer.

Hempel, C. G., and P. Oppenheim. 1948. 'Studies in the Logic of Explanation.' Philosophy of Science 15 (2): 135-75.

Heyse, V., J. Erpenbeck, and S. Ortmann. 2015. 'Einleitung: Ein Meer von Kompetenzen.' In Kompetenz ist viel mehr: Erfassung und Entwicklung von fachlichen und überfachlichen Kompetenzen in der Praxis, edited by V. Heyse, J. Erpenbeck, and S. Ortmann, 13-8. Münster and New York: Waxmann. 
Hösle, V. 2018. Kritik der verstehenden Vernunft: Eine Grundlegung der Geisteswissenschaften. München: C. H. Beck.

Julmi, C. 2020. “Nun sag, wie hast du's mit den Geisteswissenschaften?" Ein Review wissenschaftstheoretischer Grundlagen deutschsprachiger Lehrbücher der Allgemeinen Betriebswirtschaftslehre.' Schmalenbachs Zeitschrift für betriebswirtschaftliche Forschung 72:95-120.

Kahneman, D. 2012. Schnelles Denken, langsames Denken. München: Siedler.

Kauffeld, S. 2011. Arbeits-, Organisations- und Personalpsychologie. Heidelberg: Springer Medizin.

Kollmann, T. 2020. Digital Leadership. Wiesbaden: Springer Gabler.

Kühl, S. 2011. Organisationen: Eine sehr kurze Einführung. Wiesbaden: vs Verlag.

Kreutzer, R. T., T. Neugebauer, and A. Pattloch. 2017. Digital Business Leadership. Wiesbaden: Springer Gabler.

Mack, O., and A. Khare. 2016. 'Perspektives on a vuc A World.' In Managing in a VUCA World, edited by O. Mack, A. Khare, A. Krämer, and T. Burgatz, 3-20. Wiesbaden: Springer.

Moltke, H. von. 1993. 'Aus den Verordnungen für die höheren Truppenführer vom 24. Juni 1869.' In Kriegstheorie und Kriegsgeschichte, edited by C. von Clausewitz and H. von Moltke, 433-59. Frankfurt am Main: Deutscher Klassiker Verlag.

Pistorius, J. 2020. 'Industrie 4.0 - vierte industrielle Revolution.' In Industrie 4.o Schlüsseltechnologien für die Produktion: Grundlagen Potentiale Anwendungen, edited by J. Pistorius, 5-7. Wiesbaden: Springer.

Radziwon, A., A. Bilberg, M. Bogers, and E. S. Madsen. 2014. 'The Smart Factory: Exploring Adaptive and Flexible Manufactoring Solutions' Procedia Engineering Solutions 69:1184-90.

Schuh, G., M. Riesener, J.-P. Prote, C. Dölle, M. Molitor, S. Schloesser, Y. Liu, and J. Titte. 2020. 'Agile Entwicklung und Produktion im Internet of Produktion.' In Handbuch Industrie 4.o: Recht, Technik, Gesellschaft, edited by W. Frenz, 467-87. Wiesbaden: Springer.

Schumpeter, J. A. 2018. Kapitalismus, Sozialismus und Demokratie. 9th ed. Tübingen: Franke.

Unkrig, E. R. 2020. Mandate der Führung 4.o. Wiesbaden: Springer Gabler. Wagner, D. J. 2018. Digital Leadership: Kompetenzen - Führungsverhalten - Umsetzungsem-pfehlungen. Wiesbaden: Springer Fachmedien. 